\title{
Statistical analysis of energy consumption, tool wear and surface roughness in machining of Titanium alloy (Ti-6Al-4V) under dry, wet and cryogenic conditions
}

\author{
Muhammad Ali Khan ${ }^{1}$, Syed Husain Imran Jaffery ${ }^{1}$, Mushtaq Khan ${ }^{1}$, Muhammad Younas ${ }^{1}$, \\ Shahid Ikramullah Butt ${ }^{1}$, Riaz Ahmad ${ }^{1}$, and Salman Sagheer Warsi ${ }^{2}$ \\ ${ }^{1}$ Department of Design and Manufacturing Engineering (DME), School of Mechanical and Manufacturing \\ Engineering (SMME), National University of Sciences and Technology (NUST), \\ Sector H-12, Islamabad, 44000, Pakistan \\ ${ }^{2}$ Department of Mechanical Engineering, Capital University of Sciences and Technology (CUST), \\ Islamabad, 44000, Pakistan \\ Correspondence: Mushtaq Khan (mkhan@smme.nust.edu.pk)
}

Received: 29 August 2019 - Revised: 20 October 2019 - Accepted: 1 November 2019 - Published: 4 December 2019

\begin{abstract}
Productivity and economy are key elements of any sustainable manufacturing system. While productivity is associated to quantity and quality, economy focuses on energy efficient processes achieving an overall high output to input ratio. Machining of hard-to-cut materials has always posed a challenge due to increased tool wear and energy loss. Cryogenics have emerged as an effective means to improve sustainability in the recent past. In the present research the use of cooling conditions has been investigated as an input variable to analyze its effect on tool wear, specific cutting energy and surface roughness in combination with other input machining parameters of feed rate, cutting speed and depth of cut. Experimental design was based on Taguchi design of experiment. Analysis of Variance (ANOVA) was carried out to ascertain the contribution ratio of each input. Results showed the positive effect of coolant usage, particularly cryogenic, on process responses. Tool wear was improved by $33 \%$ whereas specific cutting energy and surface roughness were improved by $10 \%$ and $9 \%$ respectively by adapting the optimum machining conditions.
\end{abstract}

In the present day world major efforts are made to ensure that industry processes are as productive and efficient as possible. From year $1751-2000$ around $337 \times 10^{9} \mathrm{tCO}_{2}$ was emitted into the atmosphere leading to global warming as well as environmental degradation (Jaffery et al., 2014). The industrial sector accounts for around $26 \%$ of the total $\mathrm{CO}_{2}$ emissions (Birol, 2017). Manufacturing sectors accounts for almost $50 \%$ of these emissions. Environmental concerns as well as energy security issues have focused research towards sustainability, productivity and economy of manufacturing processes. This has led towards the objective of process optimization where output responses are augmented by careful selection of input parameters.
Machining is a major sector in the manufacturing industries capable of producing parts with precision and accuracy working with different materials like metals, non metals and polymers (Childs et al., 2000). Machining accounts for almost $10 \%$ of all manufacturing industry energy consumption (Zhao et al., 2016). In various industries turning represents a major chunk of machining processes while in the aerospace industry turning accounts for almost $85 \%$ of the total machining time in an aircraft engine (Bermingham et al., 2012a). While pure Titanium may not fulfill requisite engineering needs being soft its alloys holds the central place in a number of industries including aerospace (Ezugwu et al., 2003), marine (Ezugwu and Wang, 1997) \& medical fields (Lundgren et al., 1997). Owing to its good corrosion resistance and elevated ratio of strength to weight titanium alloys are the preferred choice for making parts like compressor 
blades, fasteners and exhaust shrouds in aerospace industry (Boyer, 1996). About $60 \%$ of all titanium alloy usage consists of Ti-6Al-4V (López de lacalle et al., 2000) because of its excellent properties as shown in Table 1.

Machining of titanium alloys presents several challenges in terms of tool life and machinability. Its low thermal conductivity raises temperature of cutting face significantly reducing tool life (Donachie, 2000). The elevated temperature strength associated with titanium alloys causes deformation of the cutting tool (Ezugwu et al., 2003). Chatter and tolerance issues arise because of lower elastic modulus (Bridges and Magnus, 2001). Its chemical reactivity acts as catalyst in wear inducing mechanisms (Hong et al., 2001). Although dry cutting has greatly been favored due to environmental concerns associated with oil based coolants, use of cooling media requires due attention while in pursuit of improving overall efficiency because of the hard-to-cut status of titanium alloys

Keeping in view titanium tool wear researchers have recommended cutting velocity between $30-60 \mathrm{~m} \mathrm{~min}^{-1}$ (Komanduri and Von Turkovich, 1981; Kitagawa et al., 1997) but that comes at the cost of productivity. In order to increase the speed from 60 to $120 \mathrm{~m} \mathrm{~min}^{-1}$ and even beyond (industry goal is $100 \mathrm{~m} \mathrm{~min}^{-1}$ and above; Bermingham et al., 2011) the employment of coolant comes in. The use of a coolant is quite well known practice ranging from traditional high pressure coolant (HPC) (Sivaiah and Chakradhar, 2018; Sun et al., 2015) to minimum quantity lubrication (MQL) (Kaynak et al., 2014; Senevirathne and Punchihewa, 2017; Khatri and Jahan, 2018) and then with the introduction of cryogenic coolants (Aramcharoen, 2016; Bagherzadeh and Budak, 2018; Bermingham et al., 2011; Bordin et al., 2015; Zhao and Hong, 1992a; Lu et al., 2018; Hong et al., 1999) i.e. Liquid Nitrogen, Argon to name a few. The cost effects of coolant needs to be weighed against advantages as coolants accounts for almost $20 \%$ of the total manufacturing cost (Shokrani et al., 2012; Sreejith and Ngoi, 2000). This important aspect will be taken up as future work by the authors. Bermingham et al. (2011) had concluded that correct selection of machining parameters are as effective in enhancing tool life as the use of coolant. Nevertheless higher productivity and economy can be achieved by use of suitable coolant at already optimized machining parameters. Optimization can be performed by determining the best machining conditions for a particular response. Researchers have optimized different machining responses of various work piece materials taking into consideration diverse input parameters (Debnath et al., 2016; Asiltürk and Neşeli, 2012; Mia and Dhar, 2017; Younas et al., 2019). Prasanna et al. (2014) considered feed, speed and air pressure during dry drilling of Ti-6Al-4V to optimize overcut, taper circularity and cutting forces. Researchers found that thrust force mainly depends on spindle speed along with feed rate whereas drilling dimensional accuracy is influenced by spindle speed and air pressure. Surface integrity and temperature were optimized by Escamilla-Salazar et al. (2013) in milling of Ti alloy by applying the particle swarm technique. It was shown that machining optimization can be achieved using swarm technique with substantial validity. Hashmi et al. (2016) optimized surface roughness during Ti-6Al-4V milling. Research showed surface integrity is mainly reliant on depth of cut. Surface integrity and tool life were optimized by Hasçalık and Çaydaş (2008) turning Ti-6Al-4V. Results found tool life highly dependent on cutting depth. Surface roughness was mainly affected by cutting speed. Zain et al. (2010) optimized surface roughness using simulated annealing in end milling. Feed, speed and rake angle were the input parameters. It was concluded that highest speed and rake angle resulted in lowest surface roughness at lowest feed values. Sarıkaya and Güllü (2015) selected cutting speed and cutting fluid flow rate to minimize surface roughness and tool wear during turning of Haynes 25 alloy. Process optimization was reached at cutting speed of $30 \mathrm{~m} \mathrm{~min}^{-1}$ and flow rate of $180 \mathrm{~mL} \mathrm{~h}^{-1}$. Earlier researchers carried out turning of Ti-6Al-4V to optimize different responses (Mia et al., 2017). Cooling condition (dry and HPC) was selected as an input parameter in addition to feed and cutting speed. Mono objective optimization showed that surface roughness and cutting forces were optimized at $0.12 \mathrm{~mm} \mathrm{rev}^{-1}$ feed and $156 \mathrm{~m} \mathrm{~min}^{-1}$ speed under wet cutting. On the other hand cutting temperature and friction coefficient were optimized at $0.12 \mathrm{~mm} \mathrm{rev}^{-1}$ feed and $78 \mathrm{~m} \mathrm{~min}^{-1}$ speed under dry conditions. Another study of the same authors incorporated cryogenic cutting along with dry cutting in turning of Ti-6Al-4V (Mia et al., 2019). Feed and speed were taken as other input parameters. Different configurations of cryogenic cutting were analyzed. It was found that dual jet configurations operating at cutting speed of $140 \mathrm{~m} \mathrm{~min}^{-1}$ and feed of $0.16 \mathrm{~mm} \mathrm{rev}^{-1}$ optimized the collective output of tool wear, surface roughness and specific cutting energy. The motivation of present study was to combine dry, wet and cryogenic conditions as a single input variable for comparison. In addition depth of cut was also incorporated to study its effect on output responses. Novelty was based on the fact that cooling/lubrication conditions and depth of cut vested as input variables further improve the sustainability and efficiency of the manufacturing system. This research is based on the concept that productivity is the cross product of quality, utilization and efficiency (Laperrire and Reinhart, 2014). These words encompass the manufacturing process taking into account vital signs like energy, wear and output quality. These responses are optimized using constructive combinations of input parameters including feed, speed and depth of cut. Taguchi design of experiment is adopted to collectively optimize the input parameters which otherwise behave differently for different responses. The aim is to formulate and optimize responses in terms of input parameters which are sustainable and productive at the same time. 
Table 1. Comparison of aerospace alloys properties (Jaffery et al., 2015).

\begin{tabular}{|c|c|c|c|c|c|c|}
\hline \multirow[t]{2}{*}{ Property } & \multicolumn{6}{|c|}{ Material } \\
\hline & Titanium & Ti-6Al-4V & Ti-6Al-6V-2Sn & $\mathrm{Ti}-10 \mathrm{~V}-2 \mathrm{Fe}-3 \mathrm{Al}$ & Inconel 718 & Al 7075-T6 Alloy \\
\hline Density $\left(\mathrm{g} \mathrm{cm}^{-3}\right)$ & 4.5 & 4.43 & 4.54 & 4.65 & 8.22 & 2.81 \\
\hline Hardness (HRC) & 10-12 (equivalent) & $30-36$ & 38 & 32 & $38-44$ & $\sim 7$ (equivalent) \\
\hline Ultimate Tensile Strength (MPa) & 220 & 950 & 1050 & 970 & 1350 & 572 \\
\hline Yield strength (MPa) & 140 & 880 & 980 & 900 & 1170 & 503 \\
\hline Modulus of elasticity (GPa) & 116 & 113.8 & 110 & 110 & 200 & 71.7 \\
\hline Ductility $(\%)$ & 54 & 14 & 14 & 9 & 16 & 11 \\
\hline Fracture toughness $\left(\mathrm{MPa} \mathrm{m}^{1 / 2}\right)$ & 70 & 75 & 60 & - & 96.4 & $20-29$ \\
\hline Thermal Conductivity $\left(\mathrm{W} \mathrm{mK}^{-1}\right)$ & 17 & 6.7 & 6.6 & 7.8 & 11.4 & 130 \\
\hline Max. operating temperature $\left({ }^{\circ} \mathrm{C}\right)$ & $\sim 150$ & 315 & 315 & 315 & 650 & - \\
\hline
\end{tabular}

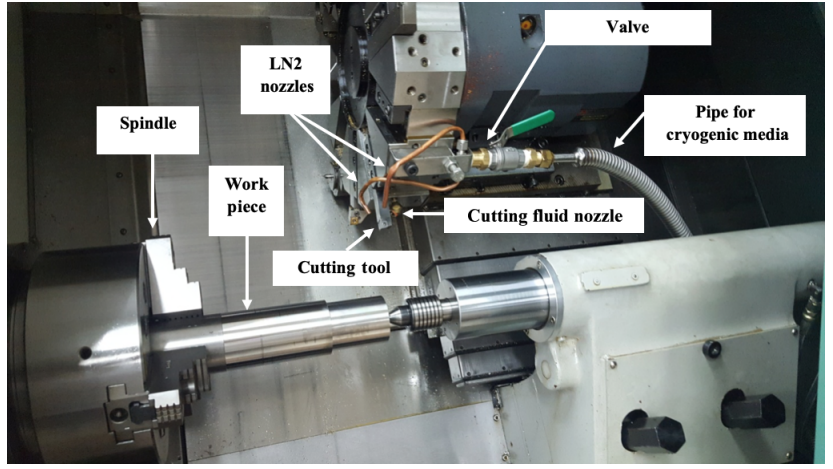

Figure 1. Experimental setup with add-on cryogenic apparatus.

Table 2. Chemical Composition (wt \%) of Ti-6Al-4V.

\begin{tabular}{lrrrrr}
\hline $\mathrm{Ti}$ & $\mathrm{V}$ & $\mathrm{Al}$ & $\mathrm{Fe}$ & $\mathrm{Cu}$ & $\mathrm{Cr}$ \\
\hline 89.44 & 4.2 & 5.7 & 0.15 & 0.003 & 0.0023 \\
\hline
\end{tabular}

\section{Experimental details}

\subsection{Experimental setup}

Computerized numerical control (CNC) turning center ML300 (Rated power $26 \mathrm{KW}$ and maximum spindle speed 3500 RPM) as shown in Fig. 1 was used for turning operation of Ti-6Al-4V bar. Table 2 displays the chemical composition of work piece. Straight carbide cutting inserts supplied by SANDVIK CCMW 09 T3 $04 \mathrm{H} 13$ (uncoated with $0^{\circ}$ rake angle) were used. Carbide tool is recommended for machining titanium based alloys because of its impact strength and toughness over varying temperature ranges (Zhao and Hong, 1992b). Each experimental run was carried out with a new insert for inspection and record. Power calculations were done using clamp on Yokogawa Power Analyzer CW-240-F meter. Roughness tester TR 110 meter was used to determine surface roughness. It had a measuring range of $0.05-10.0 \mu \mathrm{m}$.

Dry, wet and cryogenic conditions were used during experimentation on equipment shown in Fig. 2. Internal cool-

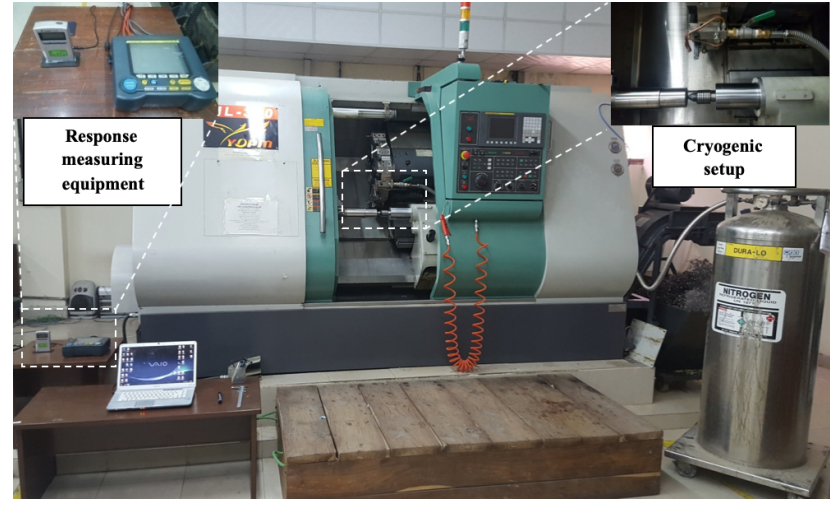

Figure 2. CNC Turning centre with cryogenic setup and response measuring equipment.

ing system of CNC Turning center ML-300 was used for wet conditions. It has a coolant pump of $0.8 \mathrm{~kW}$ rating which uses water based coolant oil shell dromus B. A steady flow rate of $6 \mathrm{~L} \mathrm{~min}^{-1}$ was maintained during wet cutting. High pressure cylinder XL-160 was used in the cryogenic setup. It can store $160 \mathrm{~L}$ of cryogenic media. Liquid nitrogen was selected as cryogenic media because of its effectiveness with titanium work material and carbide tool combination (Hong, 2006). Due to its worldwide availability and inert nature LN2 is the most widely used cryogenic media (Jawahir et al., 2016). Pressure of 20 psi was maintained using a pressure regulator developing a flow rate of $4 \mathrm{~L} \mathrm{~min}^{-1}$. Vacuum insulated pipes were used to carry the media to two copper pipes with $4 \mathrm{~mm}$ dia through a bifurcated cryogenic needle valve. Previous researches (Bermingham et al., 2012b; Hong and Ding, 2001; Mia et al., 2019) have found that using dual jets one each at flank and rake face produced optimum results.

\subsection{Response measurement}

Measured responses included specific cutting energy (SCE), tool wear rate $(R)$, surface roughness $(\mathrm{Ra})$ and material removal rate (MRR). Multiple readings were taken which were averaged for accuracy. ISO 3685 was followed for tool wear 


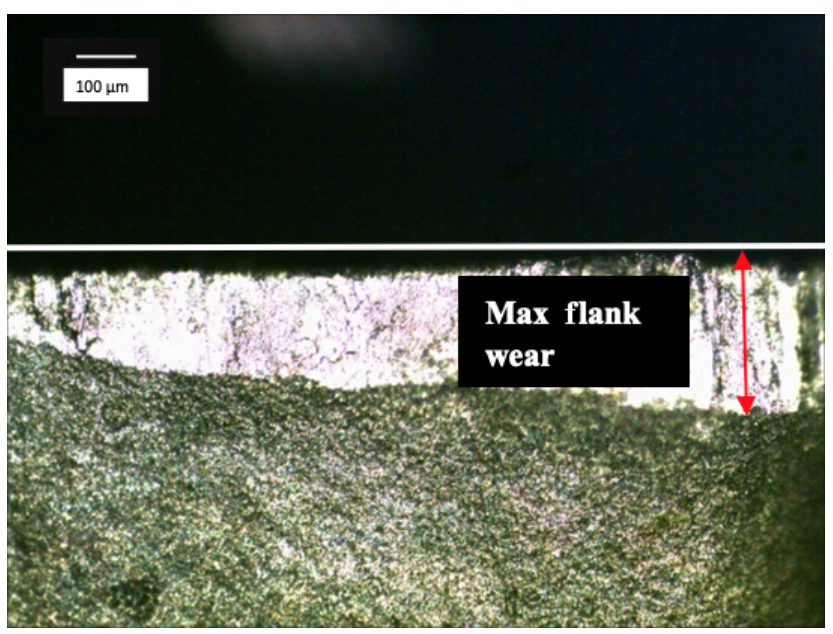

Figure 3. Optical microscopy image showing maximum flank wear.

verdict which says that criteria of flank wear (VB) is either average 0.3 or maximum $0.6 \mathrm{~mm}$. Optical microscopy was used for wear measurement as shown in Fig. 3.

Since accuracy and product quality are highly influenced by flank wear it is mostly considered in industrial machining (Jaffery and Mativenga, 2008). Moreover flank wear is related to substrate properties, whereas crater wear reflects coating properties (Fitzsimmons and Sarin, 2001). $R$ was calculated using Eq. (1). A lower tool wear will be symbolized by a higher negative value of $R$ (Jaffery and Mativenga, 2009, 2008).

$R=\log \left[\frac{\mathrm{VB}}{l_{\mathrm{s}}}\right]=\left[\frac{\mathrm{VB}}{1000 t V_{c}}\right]$

where $l_{\mathrm{S}}$ is spiral length and $t$ is the cutting time. SCE (amount of energy required to remove unit volume of material) was calculated using Eq. (2). It must be noted that efficiency or type of CNC machine has no effect on SCE.

$\operatorname{SCE}\left(\mathrm{J} \mathrm{mm}^{-3}\right)=\frac{P_{\text {cut }}(\mathrm{W})}{\operatorname{MRR}\left(\mathrm{mm}^{3} \mathrm{~s}^{-1}\right)}$

$P_{\text {cut }}(\mathrm{W})$ was calculated employing a two cycle approach making use of Eq. (3). The two cycle approach refers to practice of measuring power twice for the same input parameters i.e. $P_{\text {actual }}$ and $P_{\text {air }}$ where $P_{\text {actual }}$ is the actual cutting power whereas $P_{\text {air }}$ is power consumed during an offset air cut. Their difference gives $P_{\text {cut }}$ which is the actual power utilized in cutting operation. $P_{\text {cut }}$ is therefore independent of machine/tool type and rating. MRR i.e. the amount of volume removed per unit time was determined using Eq. (4).

$$
P_{\text {cut }}(\mathrm{W})=P_{\text {actual }}(\mathrm{W})-P_{\text {air }}(\mathrm{W})
$$

MRR $=f \times v \times d$

Equation (3) is an effective method for measurement of power utilized during cutting operation (Li and Kara, 2011;
Table 3. Selected input machining parameters.

\begin{tabular}{lrrrl}
\hline Parameters & $\begin{array}{r}\text { Feed } \\
\text { rate } \\
\left(\mathrm{mm} \mathrm{rev}^{-1}\right)\end{array}$ & $\begin{array}{r}\text { Cutting } \\
\text { speed } \\
\left(\mathrm{m} \mathrm{min}^{-1}\right)\end{array}$ & $\begin{array}{r}\text { Depth } \\
\text { of cut } \\
(\mathrm{mm})\end{array}$ & $\begin{array}{l}\text { Cooling/ } \\
\text { lubrication } \\
\text { conditions }\end{array}$ \\
\hline Level 1 & 0.12 & 50 & 1 & Dry \\
Level 2 & 0.16 & 100 & 1.5 & Wet \\
Level 3 & 0.20 & 150 & 2 & Cryogenic \\
\hline
\end{tabular}

Table 4. Taguchi Orthogonal Array (L9) of cutting parameters.

\begin{tabular}{lrrrr}
\hline Run & $\begin{array}{r}\text { Feed } \\
\text { rate } \\
\left(\mathrm{mm} \mathrm{rev}^{-1}\right)\end{array}$ & $\begin{array}{r}\text { Cutting } \\
\text { speed } \\
\left(\mathrm{m} \mathrm{min}^{-1}\right)\end{array}$ & $\begin{array}{r}\text { Depth } \\
\text { of cut } \\
(\mathrm{mm})\end{array}$ & $\begin{array}{r}\text { Cooling/ } \\
\text { lubrication } \\
\text { conditions* }^{*}\end{array}$ \\
\hline 1 & 0.12 & 50 & 1 & 1 \\
2 & 0.12 & 100 & 1.5 & 2 \\
3 & 0.12 & 150 & 2 & 3 \\
4 & 0.16 & 50 & 1.5 & 3 \\
5 & 0.16 & 100 & 2 & 1 \\
6 & 0.16 & 150 & 1 & 2 \\
7 & 0.20 & 50 & 2 & 2 \\
8 & 0.20 & 100 & 1 & 3 \\
9 & 0.20 & 150 & 1.5 & 1 \\
\hline
\end{tabular}

$* 1=$ dry, $2=$ wet and $3=$ cryogenic.

Warsi et al., 2018, 2017). It must be noted that while calculating the $P_{\text {air }}$ and $P_{\text {actual }}$ utmost care was taken to avoid unnecessary or exaggerated points corresponding to rapid tool travel just before/after cut finished.

\subsection{Design of experiment}

Feed rate, cutting speed, depth of cut and cooling/lubrication conditions were taken as input variables. It can be concluded from literature (Behera et al., 2017; Warsi et al., 2018) that these variables have significant effect on machining output response. Table 3 shows selected levels of input parameters keeping in view tool manufacturer guidelines (Sandvik, 2015) and ISO standard (1993).

Taguchi design of experiment was preferred over full factorial because of its overall efficiency in term of lesser runs (Ross and Ross, 1988). Table 4 displays the formulated Taguchi design orthogonal array.

\section{Results and discussion}

The experimental results of measured responses are tabulated in Table 5. Each response was measured twice by repetition of experimental run.

Best and worst values of any response can be seen albeit within the avail combination of cutting parameters and in isolation with each other. To draw useful information from ex- 
Table 5. Measured responses during experimentation.

\begin{tabular}{lrr|rr|rr}
\hline \multirow{2}{*}{ Run } & \multicolumn{2}{c|}{ Wear rate $(R)$} & \multicolumn{2}{c|}{$\mathrm{Ra}(\mu \mathrm{m})$} & \multicolumn{2}{c}{$\mathrm{SCE}\left(\mathrm{J} \mathrm{mm}^{-3}\right)$} \\
\cline { 2 - 7 } & Trial A & Trial B & Trial A & Trial B & Trial A & Trial B \\
\hline 1 & -6.1684 & -6.2044 & 1.51 & 1.53 & 1.1004 & 1.1504 \\
2 & -6.1408 & -6.1797 & 1.19 & 1.21 & 1.2338 & 1.3005 \\
3 & -5.9364 & -5.9564 & 1.13 & 1.15 & 1.2005 & 1.2338 \\
4 & -6.1815 & -6.2215 & 1.82 & 1.84 & 1.0004 & 1.0754 \\
5 & -5.7789 & -5.7845 & 1.75 & 1.77 & 1.1630 & 1.2192 \\
6 & -5.7489 & -5.7877 & 1.61 & 1.63 & 1.3005 & 1.3756 \\
7 & -5.9325 & -5.9525 & 2.96 & 2.98 & 1.0804 & 1.1104 \\
8 & -5.8682 & -5.8924 & 2.61 & 2.63 & 1.1104 & 1.1705 \\
9 & -5.1689 & -5.1959 & 2.66 & 2.68 & 1.2405 & 1.2805 \\
\hline
\end{tabular}

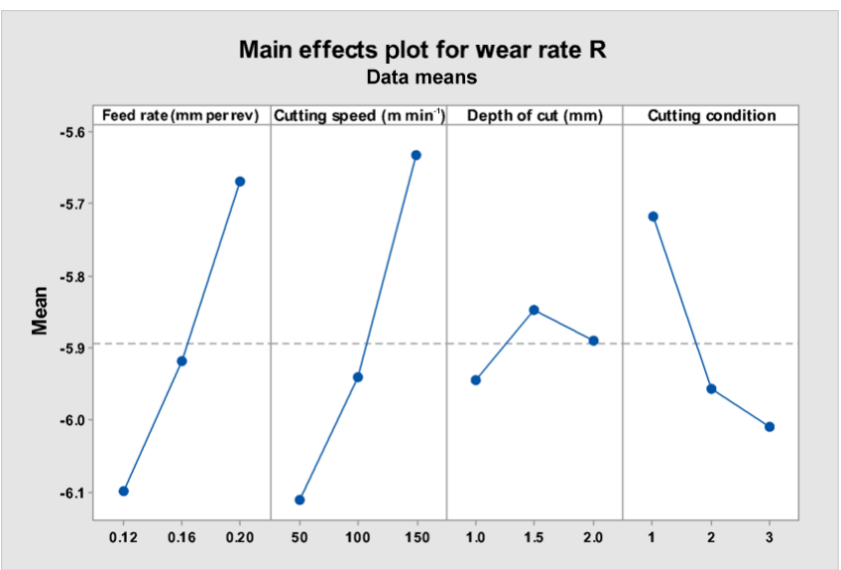

Figure 4. Main effects plot for $R$.

perimental results each response was individually plotted and analyzed.

\subsection{Effects on tool wear}

Flank wear (VB) of each run was measured using optical microscopy. Tool wear rate was calculated from Eq. (1). Main effects plot of $R$ is shown in Fig. 4. It shows that wear rate increases with increasing feed and speed. Cutting depth displays an inconsistent response by initially increasing and then decreasing. In terms of coolant usage cryogenic condition has significantly reduced $R$ as shown in the Fig. 4.

The increase of wear rate with increasing feed can be attributed to lower rate of heat dissipation (Sarwar et al., 2009). Enhanced vibration at tool-work piece interface at higher feed values also contributes towards higher wear (Yan and $\mathrm{Li}, 2013)$. Titanium by virtue of its lower thermal conductivity gets heated up particularly at high cutting speed reaching in excess of $800^{\circ} \mathrm{C}$ (Ezugwu and Wang, 1997) as temperature of cutting zone is directly proportional to cutting speed (Fan et al., 2016; Shaw, 2005). Figure 5 displays the relationship between cutting speed and temperature. Since all wear mechanisms are directly proportional to heat the tool wears out at an aggravated rate when machined at elevated speed

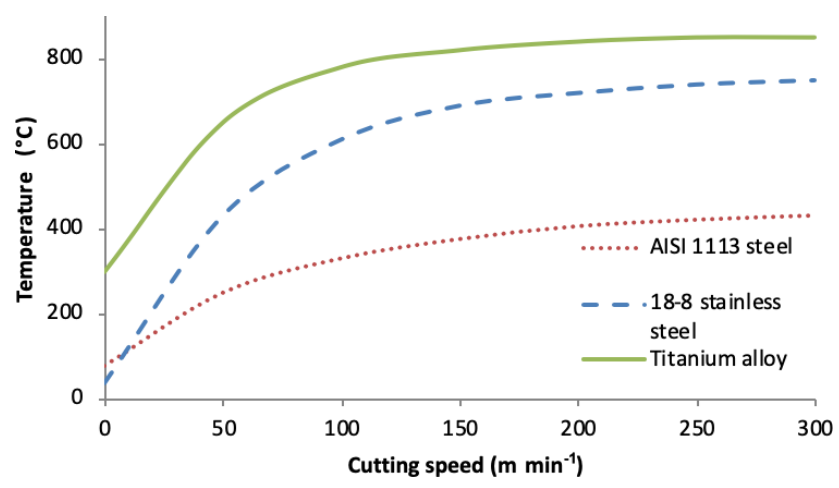

Figure 5. Relationship between cutting speed and temperature for different materials (data from Shaw, 2005).

values especially under dry conditions. Diffusion dissolution and abrasion wear mechanisms, which are the primary causes (Bermingham et al., 2012b) of tool failure increases manifolds with increasing heat in cutting zone. This is the reason why the worst tool wear is expected to be in dry conditions at max feed and speed as shown by earlier researchers (Ahsan et al., 2012; Kumar and Choudhury, 2008; Venugopal et al., 2007; Bermingham et al., 2011; Sun et al., 2010a).

The liquid nitrogen media provides a temperature of $-196^{\circ} \mathrm{C}$ in the cutting zone (Bermingham et al., 2011). Generally coolants are more efficient at lower values of speed and feed (Venugopal et al., 2007). The reason for this observation is that the coolant can penetrate cutting zone easily at lower speed and feed. Also Bermingham et al. (2011) found that cryogenic media enhances tool life by mainly preventing the production and hence transfer of heat to tool and to a lesser extent by extricating the heat produced. This is because cryogenic media reduces contact length between tool-chip and resultantly reduces the frictional heat generated. ANOVA was performed to determine the influence of each factor on tool wear as shown in Table 6.

Values of $S$ and $R$-Sq (pred) indicates that experimental data can be used to predict other value points with validity. The $P$ value indicates that all factors are substantially contributing the response. The main contributing factor for $R$ comes out to be speed $(44.39 \%)$ closely followed by feed $(35.15 \%)$.

\subsection{Effects on specific cutting energy}

Specific cutting energy $\left(\mathrm{J} \mathrm{mm}^{-3}\right)$ is plotted against the input parameters as shown in Fig. 6. SCE is decreasing with increasing feed and decreasing speed as shown in Fig. 6. As for speed Warsi et al. (2018) showed an opposite behavior i.e. decreasing SCE with increasing speed as shown in Fig. 7. The SCE denoted with a dotted line shows a decrease as the speed is increased with an increasing trend around $1000 \mathrm{~m} \mathrm{~s}^{-1}$. An argument can arise that present research is at cutting speed of 50 to $150 \mathrm{~m} \mathrm{~min}^{-1}$ as opposed to 250 to 
Table 6. ANOVA for Wear rate $R$.

\begin{tabular}{lrrrrrrr}
\hline Source & DF & Seq SS & Adj SS & Adj MS & $F$ Value & $P$ Value & CR \\
\hline$f\left(\mathrm{~mm} \mathrm{rev}^{-1}\right)$ & 2 & 0.55751 & 0.557511 & 0.278755 & 622.48 & 0.000 & $35.15 \%$ \\
$v\left(\mathrm{~m} \mathrm{~min}^{-1}\right)$ & 2 & 0.70410 & 0.704104 & 0.352052 & 786.16 & 0.000 & $44.39 \%$ \\
$d(\mathrm{~mm})$ & 2 & 0.02836 & 0.028358 & 0.014179 & 31.66 & 0.000 & $1.79 \%$ \\
CC & 2 & 0.29205 & 0.292055 & 0.146027 & 326.09 & 0.000 & $18.41 \%$ \\
Error & 9 & 0.00403 & 0.004030 & 0.000448 & & & $0.25 \%$ \\
\hline Total & 17 & 1.58606 & & & & & $100.00 \%$ \\
\hline
\end{tabular}

$\mathrm{SD}=0.0211616, R-\mathrm{Sq}=99.75 \%, R-\mathrm{Sq}($ pred $)=98.98 \%$

$\mathrm{DF}$ - degrees of freedom, $\mathrm{SS}$ - sum of squares, MS - mean squares, $F-F$ value, $P-P$ value, $\mathrm{CR}-$ contribution ratio $(\%)$, $\mathrm{SD}$ - standard deviation, $R$-Sq.(pred) - predicted $R^{2}$.

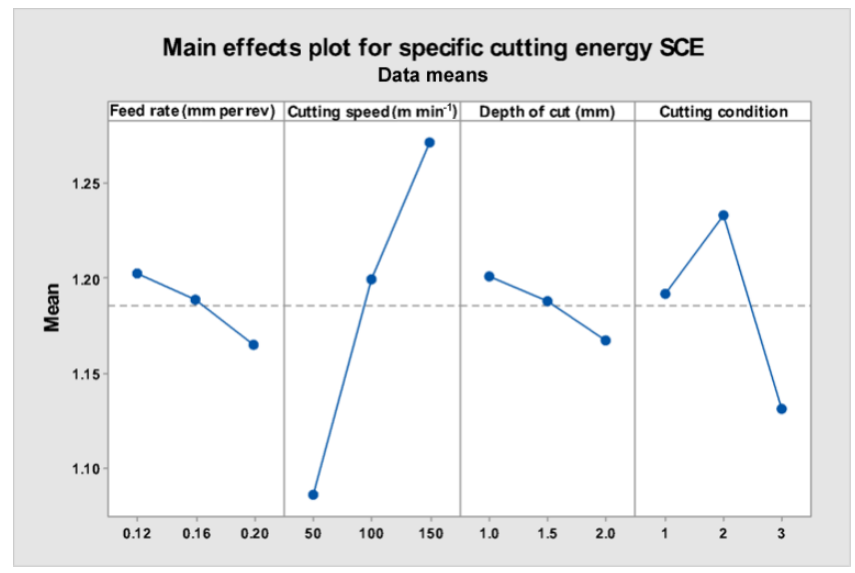

Figure 6. Main effects plot for SCE.

$1500 \mathrm{~m} \mathrm{~min}^{-1}$ speed considered by Warsi et al. (2018). To confirm the independence of this fact, turning of $\mathrm{Al}$ was also carried out at same speed. The result showed that $\mathrm{Al}$ even at the present research speed displayed a decrease in SCE with increasing speed.

Another important point is the cutting speed categories which were considered in both the cases as chalked out by Schulz and Moriwaki (1992) as shown in Fig. 8. It was found that both the cutting speeds were in transitional range in their respective domains, i.e. 50 to $150 \mathrm{~m} \mathrm{~s}^{-1}$ in case of titanium and 250 to $1500 \mathrm{~m} \mathrm{~s}^{-1}$ in case of aluminum. It can be said that both titanium and aluminum showed comparatively same trend in same category (transition). The findings are aligned with results of Pervaiz et al. (2013) which concluded that cutting forces increases by increasing speed above $60 \mathrm{~m} \mathrm{~min}^{-1}$ during turning of Ti-6Al-4V.

During turning a number of forces acts in certain directions as described in merchants circle (Shaw, 2005). These forces which plays a vital role in SCE and for that matter in tool wear usually decreases with increasing temperature (Kalyan and Samuel, 2015). Nevertheless, it is also reported (Schulz et al., 1981; Komanduri et al., 1984) that the cutting forces increase again after reaching a minimum value. More-

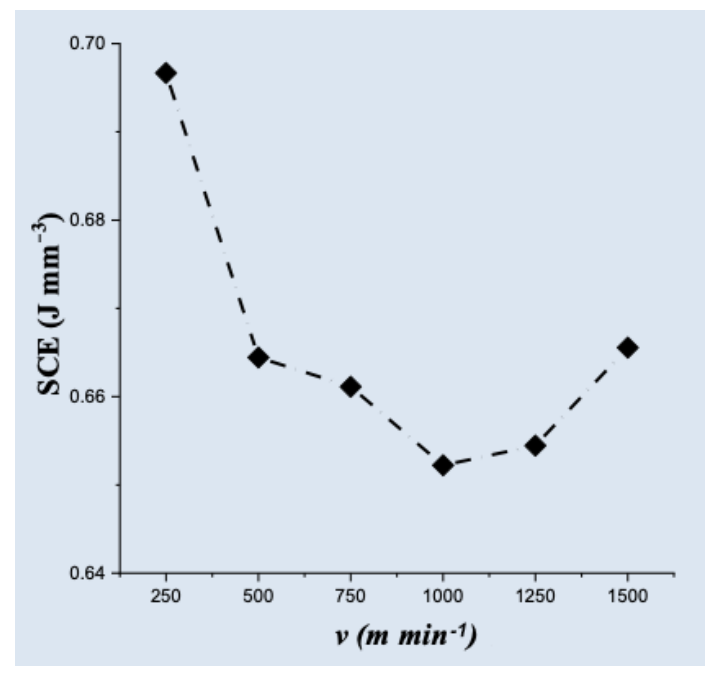

Figure 7. SCE relationship with cutting speed (data from Warsi et al., 2018).

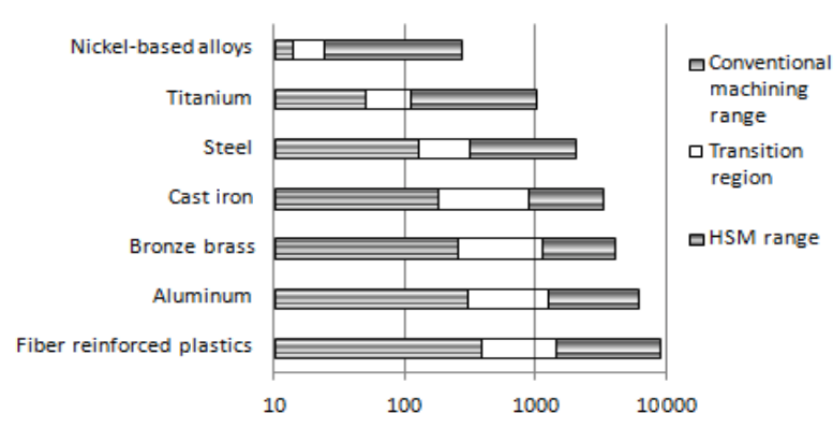

Figure 8. Cutting speed ranges for machining of different materials (data from Schulz and Moriwaki, 1992).

over with the introduction of cryogenic cooling new dimensions are added as suggested by Bermingham et al. (2011). It is concluded that SCE is a material based property and it depends on a number of external and inherent factors e.g. thermal softening occurring at higher temperatures (Sun et al., $2010 b$ ) in opposition to high temperature strength (Ezugwu 
Table 7. ANOVA for SCE.

\begin{tabular}{|c|c|c|c|c|c|c|c|}
\hline Source & DF & Seq SS & Adj SS & Adj MS & $F$ Value & $P$ Value & CR \\
\hline$f\left(\mathrm{~mm} \mathrm{rev}^{-1}\right)$ & 2 & 0.004370 & 0.004370 & 0.002185 & 1.38 & 0.301 & $2.76 \%$ \\
\hline$v\left(\mathrm{~m} \mathrm{~min}^{-1}\right)$ & 2 & 0.105097 & 0.105097 & 0.052549 & 33.08 & 0.000 & $66.28 \%$ \\
\hline$d(\mathrm{~mm})$ & 2 & 0.003412 & 0.003412 & 0.001706 & 1.07 & 0.382 & $2.15 \%$ \\
\hline $\mathrm{CC}$ & 2 & 0.031401 & 0.031401 & 0.015701 & 9.88 & 0.005 & $19.80 \%$ \\
\hline Error & 9 & 0.014297 & 0.014297 & 0.001589 & & & $9.02 \%$ \\
\hline Total & 17 & 0.158577 & & & & & $100 \%$ \\
\hline
\end{tabular}

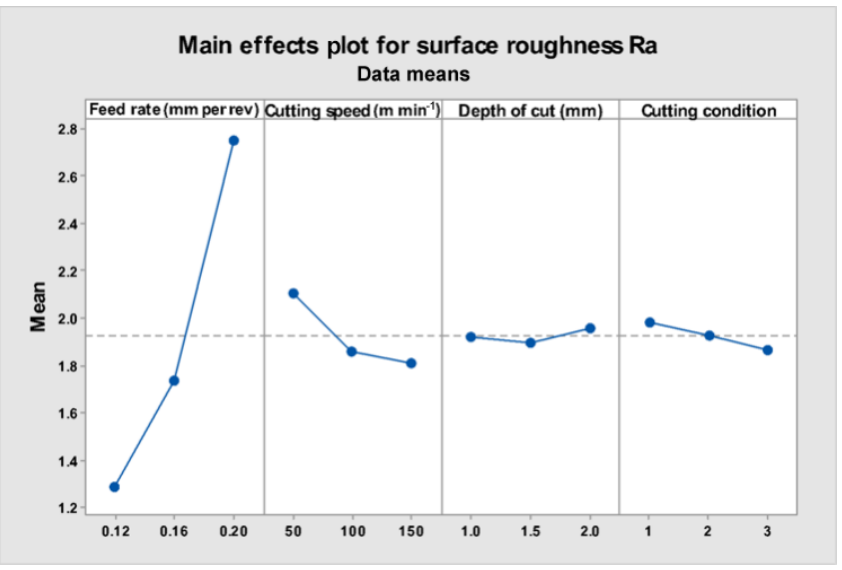

Figure 9. Main effects plot for Ra.

et al., 2003) associated with titanium alloys. Reasons for increasing SCE with speed can be ascribed to work hardening of titanium alloy during machining and aggravated tool wear at higher cutting speeds (Jaffery and Mativenga, 2008; Younas et al., 2019).

In case of cryogenic cooling, work hardening is the major contributor towards SCE as compared to thermal softening. As work hardening is known to decrease with decreasing temperature (Chichili et al., 1998), cryogenic machining $\left(-196^{\circ} \mathrm{C}\right)$ shows lower SCE in comparison with dry and wet machining. However, in case of wet and dry conditions, thermal softening plays a vital role in the SCE. With increasing temperature material softens and SCE reduces. In dry machining thermal softening effect is more pronounced as compared to wet condition thus resulting in lower SCE (Pervaiz et al., 2013).

ANOVA was performed to determine the influence of each factor on SCE. Table 7 displays the ANOVA for SCE. Analysis reveals that cutting speed with $66.28 \%$ is the most significant factor followed by cooling/lubrication conditions with $19.80 \%$. Feed and depth of cut are insignificant members.

\subsection{Effects on surface roughness}

Surface roughness is related to the overall product quality and hence measured as a vital output response. It increases with increasing feed and decreasing speed as shown in Fig. 9. Depth of cut showed inconsistent effect on Ra. The geometric contribution of feed rate is evident by its effect on Ra. High feed imparts microgroove over the surface which stretches and adds to Ra whereas low cutting speed creates BUE which induces chatter and worsens the roughness (Mia and Dhar, 2017). In another related study (Mia and Dhar, 2016) higher $\mathrm{Ra}$ was attributed to higher peaks and crest over the machined surface at greater feed values. In addition increased vibration at high feed rates also contribute towards higher $\mathrm{Ra}$ (Yan and $\mathrm{Li}, 2013)$.

Cryogenic conditions produced lowest Ra followed by wet conditions. Dry condition produced highest Ra. Better Ra with coolant is because coolant also serves as a lubricant between sliding surfaces (Dhar and Kamruzzaman, 2007). Another fact is the substantial alteration of coefficient of friction at the tool-work interface in the presence of a coolant (Strano et al., 2013). The aggravated tool wear under dry (no-coolant/lubricant) condition also increases the Ra and counteracts against the thermal softening gain. Comparable findings are reported by earlier researchers (Bordin et al., 2015; Mia, 2017). The phenomena of penetration of coolant has been reported by different authors (Mia and Dhar, 2016; Bagherzadeh and Buda, 2018; Yuan et al., 2011). The lubricating phenomena both by cryogenic and wet cutting is effective at lower cutting speed values because of the comparative ease of penetration as compared with high speed conditions (Venugopal et al., 2007). Same is evident from Fig. 9 where Ra changes drastically in the second half of speed (100 to $150 \mathrm{~m} \mathrm{~min}^{-1}$ ) and feed (0.16 to $0.20 \mathrm{~mm}$ ) as compared to the first half. Analysis of contribution of factors is tabulated in Table 8.

The $P$ value indicates that all factors are contributing towards response. Feed is the most influential parameters with $94.98 \%$ contribution ratio followed by speed with $4.24 \%$. 
Table 8. ANOVA for Surface roughness Ra.

\begin{tabular}{lrrrrrrr}
\hline Source & DF & Seq SS & Adj SS & Adj MS & $F$ Value & $P$ Value & CR \\
\hline$f\left(\mathrm{~mm} \mathrm{rev}^{-1}\right)$ & 2 & 6.77444 & 6.77444 & 3.38722 & 16936.11 & 0.000 & $94.98 \%$ \\
$v\left(\mathrm{~m} \mathrm{~min}^{-1}\right)$ & 2 & 0.30271 & 0.30271 & 0.15136 & 756.78 & 0.000 & $4.24 \%$ \\
$d(\mathrm{~mm})$ & 2 & 0.00991 & 0.00991 & 0.00496 & 24.78 & 0.000 & $0.14 \%$ \\
$\mathrm{CC}$ & 2 & 0.04338 & 0.04338 & 0.02169 & 108.44 & 0.000 & $0.61 \%$ \\
Error & 9 & 0.00180 & 0.00180 & 0.00020 & & & $0.03 \%$ \\
\hline Total & 17 & 7.13224 & & & & $100 \%$ \\
\hline $\mathrm{SD}=0.0141421$, & $R$-Sq $=99.95 \%, R$-Sq(pred $)=99.90 \%$ & & &
\end{tabular}

\section{Validation experimentation}

The focus of this research is the investigation of machining response taking into consideration the Cooling/lubrication conditions as the input variable along with other fundamental machining inputs. This methodology first necessitated the identification of contribution of vital input parameters and then selection of specific values which will contribute towards suitable results. In this study $R, \mathrm{SCE}$ and Ra were selected, based on the smaller is better model. Table 9 displays the desired values of input parameters as predicted by Taguchi methodology.

Subsequently confirmatory tests were conducted at the best and worst machining parameters combinations to validate the experimental results. Table 10 shows the results of confirmatory test in comparison with the best results obtained through Taguchi Analysis. As evident from Table 10 validation test conformed to the trends predicted using statistical analysis and Taguchi Design of Experiments. Figure 10 shows the scanning electron microscopy images of lowest and highest wear rate conditions.

\section{Conclusion}

In the present research dry, wet and cryogenic turning of Ti-6Al-4V was carried out. Focus of attention was sustainability, productivity and economy of machining process. Selected output responses included specific cutting energy, tool wear, surface roughness and material removal rate where the first two highlights sustainability and efficiency while last two represents productivity. Following conclusions can be formulated on the basis of achieved results:

- Tool Wear rate was significantly reduced by use of cryogenic and wet media. Cryogenic coolant produced the least wear result in run 4 even at elevated feed and speed conditions. This wear is $4 \%$ better than the one at lowest feed and speed under dry condition. The tool life was further improved by $33 \%$ when cryogenic machining was carried out at optimum machining parameters.

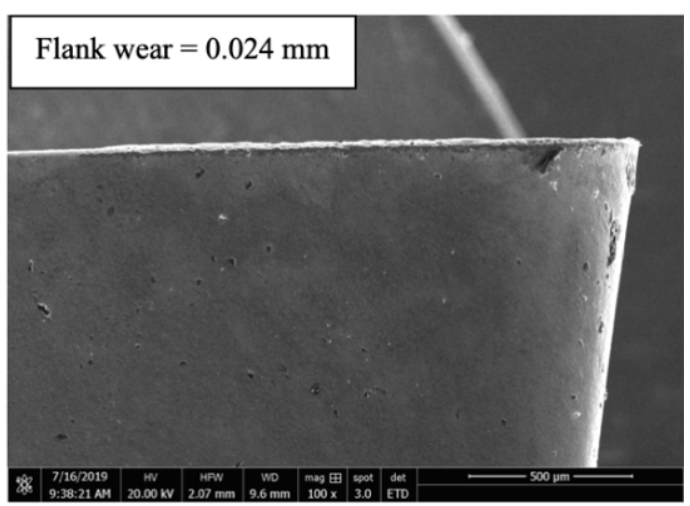

(a)

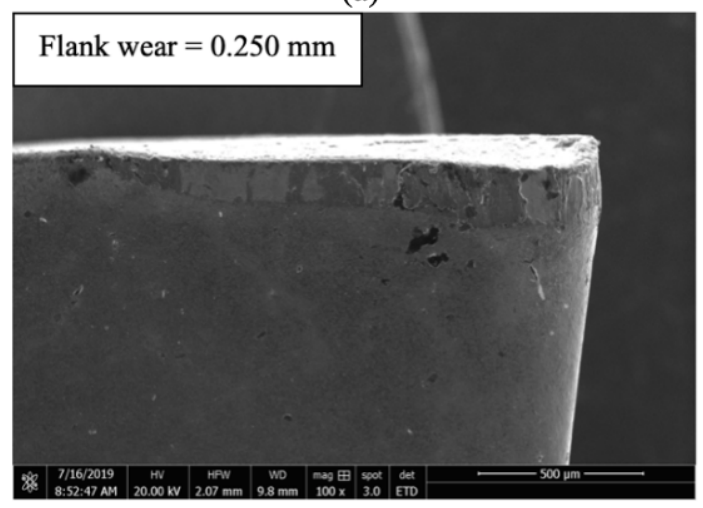

(b)

Figure 10. Scanning electron microscopy images. (a) Min wear at $f=0.12, v=50, d=1$, cryogenic. (b) Max wear at $f=0.2$, $v=150, d=1.5$, dry.

- Cutting speed had the highest contribution (44.39\%) towards tool wear followed by feed rate $(35.15 \%)$ and coolant media $(18.41 \%)$.

- Specific cutting energy in case of cryogenic machining was less as compared with dry and wet machining. About $10 \%$ improvement in energy consumption was achieved by use of optimum machining parameters under cryogenic conditions. Specific cutting energy of Ti- 
Table 9. Machining condition sets for individual best and worst responses.

\begin{tabular}{llrrrr}
\hline Responses & \multicolumn{5}{c}{ Cutting parameters } \\
\cline { 2 - 6 } & & $f\left(\mathrm{~mm} \mathrm{rev}^{-1}\right)$ & $v\left(\mathrm{~m} \mathrm{~min}^{-1}\right)$ & $d(\mathrm{~mm})$ & $\mathrm{CC}$ \\
\hline \multirow{2}{*}{ Wear rate, $R$} & Best & 0.12 & 50 & 1 & 3 \\
& Worst & 0.20 & 150 & 1.5 & 1 \\
\hline \multirow{2}{*}{$\mathrm{SCE}\left(\mathrm{J} \mathrm{mm}^{-3}\right)$} & Best & 0.20 & 50 & 2 & 3 \\
& Worst & 0.12 & 150 & 1 & 2 \\
\hline $\operatorname{Ra}(\mu \mathrm{m})$ & Best & 0.12 & 150 & 1.5 & 3 \\
& Worst & 0.20 & 50 & 2 & 1 \\
\hline
\end{tabular}

Table 10. Comparison of validation test results with initial runs.

\begin{tabular}{llrrr}
\hline Response & Condition & Validation tests & Initial runs & $\%$ age difference \\
\hline \multirow{2}{*}{ Wear rate $R$} & Best & -6.3982 & -6.2215 & $33 \%$ \\
& Worst & -5.1689 & -5.1689 & $0 \%$ \\
\hline \multirow{2}{*}{$\mathrm{SCE}\left(\mathrm{J} \mathrm{mm}^{-3}\right)$} & Best & 0.9390 & 1.0004 & $10 \%$ \\
& Worst & 1.4024 & 1.3756 & $2 \%$ \\
\hline $\mathrm{Ra}(\mu \mathrm{m})$ & Best & 0.98 & 1.13 & $9 \%$ \\
& Worst & 3.06 & 2.98 & $2 \%$ \\
\hline
\end{tabular}

$6 \mathrm{Al}-4 \mathrm{~V}$ increases with increasing speed because of its aggravated tool wear and work hardening.

- Cutting speed had significantly higher contribution towards specific cutting energy with $66.28 \%$ contribution ratio followed by coolant media (19.80\%). Feed rate and depth of cut had little effects with $2.76 \%$ and $2.15 \%$ contribution respectively.

- Higher values of speed gave better surface roughness results in contrast with higher feeds values. Use of coolant improved surface roughness because of its lubrication effect. Surface roughness was improved by $9 \%$ when machining was carried out under cryogenic conditions under optimum machining parameters.
- Surface roughness was highly influenced $(94.98 \%$ contribution ratio) by feed rate. Contribution ratio of cutting speed was $4.24 \%$ whereas cooling condition and depth of cut were having contribution of less than $1 \%$.

Data availability. No data sets were used in this article. 
Appendix A: Abbreviations

$\begin{array}{ll}\text { ANOVA } & \text { Analysis of Variance } \\ \text { CC } & \text { Cooling/lubrication Condition } \\ d & \text { Depth of cut }(\mathrm{mm}) \\ D & \text { Work piece diameter }(\mathrm{mm}) \\ f & \text { Feed rate }\left(\mathrm{mm} \mathrm{rev}^{-1}\right) \\ l & \text { Linear length of cut }(\mathrm{mm}) \\ l_{\mathrm{s}} & \text { Spiral length of cut }(\mathrm{mm}) \\ \text { MRR } & \text { Material removal rate }\left(\mathrm{cm}^{3} \mathrm{~s}^{-1}\right) \\ P_{\text {actual }}(\mathrm{W}) & \text { Total power consumed during actual cutting } \\ P_{\text {air }}(\mathrm{W}) & \text { Total power consumed during air cut } \\ P_{\text {cut }}(\mathrm{W}) & \text { Power consumed for cutting operation } \\ R & \text { Wear rate } \\ \mathrm{Ra} & \text { Surface roughness }(\mu \mathrm{m}) \\ \mathrm{SCE} & \text { Specific cutting energy } \\ t & \text { Cutting time }(\mathrm{s}) \\ v & \text { Cutting speed }\left(\mathrm{m} \mathrm{min} \mathrm{min}^{-1}\right) \\ \mathrm{VB} & \text { Flank wear }(\mathrm{mm})\end{array}$


Author contributions. MAK and MK designed experiments. MY and SSW assisted in developing methodology and plotting graphs. SHIJ supervised MAK during experimentation and tool characterization. SIB and RA reviewed drafted paper and addressed revisions.

Competing interests. The authors declare that they have no conflict of interest.

Review statement. This paper was edited by Bahman Azarhoushang and reviewed by two anonymous referees.

\section{References}

Ahsan, K. B., Mazid, A. M., Clegg, R. E., and Pang, G.: Study on carbide cutting tool life using various cutting speeds for $\alpha-\beta$ Tialloy machining, Journal of Achievements in Materials and Manufacturing Engineering, 55, 601-606, 2012.

Aramcharoen, A.: Influence of Cryogenic Cooling on Tool Wear and Chip Formation in Turning of Titanium Alloy, Proc. CIRP, 46, 83-86, https://doi.org/10.1016/j.procir.2016.03.184, 2016.

Asiltürk, I. and Neşeli, S.: Multi response optimisation of CNC turning parameters via Taguchi method-based response surface analysis, Measurement, 45, 785-794, 2012.

Bagherzadeh, A. and Budak, E.: Investigation of machinability in turning of difficult-to-cut materials using a new cryogenic cooling approach, Tribol. Int., 119, 510-520, https://doi.org/10.1016/j.triboint.2017.11.033, 2018.

Behera, B. C., Alemayehu, H., Ghosh, S., and Rao, P. V.: A comparative study of recent lubri-coolant strategies for turning of Nibased superalloy, J. Manuf. Process., 30, 541-552, 2017.

Bermingham, M. J., Kirsch, J., Sun, S., Palanisamy, S., and Dargusch, M. S.: New observations on tool life, cutting forces and chip morphology in cryogenic machining Ti-6Al-4V, Int. J. Mach. Tool. Manu., 51, 500-511, https://doi.org/10.1016/j.ijmachtools.2011.02.009, 2011.

Bermingham, M. J., Palanisamy, S., and Dargusch, M. S.: Understanding the tool wear mechanism during thermally assisted machining Ti-6Al-4V, Int. J. Mach. Tool. Manu., 62, 76-87, https://doi.org/10.1016/j.ijmachtools.2012.07.001, 2012a.

Bermingham, M. J., Palanisamy, S., Kent, D., and Dargusch, M. S.: A comparison of cryogenic and high pressure emulsion cooling technologies on tool life and chip morphology in Ti-6Al-4V cutting, J. Mater. Process. Tech., 212, 752-765, https://doi.org/10.1016/j.jmatprotec.2011.10.027, 2012b.

Birol, F.: Key world energy statistics, International Energy Agency, Paris, 2017.

Bordin, A., Bruschi, S., Ghiotti, A., and Bariani, P. F.: Analysis of tool wear in cryogenic machining of additive manufactured Ti6Al4V alloy, Wear, 328-329, 89-99, https://doi.org/10.1016/j.wear.2015.01.030, 2015.

Boyer, R. R.: An overview on the use of titanium in the aerospace industry, Mat. Sci. Eng. A-Struct., 213, 103-114, https://doi.org/10.1016/0921-5093(96)10233-1, 1996.

Bridges, P. and Magnus, B.: Manufacture of titanium alloy components for aerospace and military applications, Research and Technology Organization, France, 2001.
Chichili, D., Ramesh, K., and Hemker, K.: The high-strain-rate response of alpha-titanium: experiments, deformation mechanisms and modeling, Acta Mater., 46, 1025-1043, 1998.

Childs, T., Maekawa, K., Obikawa, T., and Yamane, Y.: Metal machining: theory and applications, Butterworth-Heinemann, John Wiley \& Sons Inc., New York, USA, 2000.

Debnath, S., Reddy, M. M., and Yi, Q. S.: Influence of cutting fluid conditions and cutting parameters on surface roughness and tool wear in turning process using Taguchi method, Measurement, 78, 111-119, 2016.

Dhar, N. and Kamruzzaman, M.: Cutting temperature, tool wear, surface roughness and dimensional deviation in turning AISI4037 steel under cryogenic condition, Int. J. Mach. Tool. Manu., 47, 754-759, 2007.

Donachie, M. J.: Titanium: a technical guide, ASM international, Materials Park, OH, 2000.

Escamilla-Salazar, I. G., Torres-Treviño, L. M., González-Ortíz, B., and Zambrano, P. C.: Machining optimization using swarm intelligence in titanium (6Al 4V) alloy, Int. J. Adv. Manuf. Tech., 67, 535-544, 2013.

Ezugwu, E. and Wang, Z.: Titanium alloys and their machinability - a review, J. Mater. Process. Tech., 68, 262-274, 1997.

Ezugwu, E., Bonney, J., and Yamane, Y.: An overview of the machinability of aeroengine alloys, J. Mater. Process. Tech., 134, 233-253, 2003.

Fan, Y., Hao, Z., Zheng, M., and Yang, S.: Wear characteristics of cemented carbide tool in dry-machining Ti-6Al-4V, Mach. Sci. Technol., 20, 249-261, 2016.

Fitzsimmons, M. and Sarin, V. K.: Development of CVD WC-Co coatings, Surface and Coatings Technology, 137, 158-163, 2001.

Hasçalık, A. and Çaydaş, U.: Optimization of turning parameters for surface roughness and tool life based on the Taguchi method, Int. J. Adv. Manuf. Tech., 38, 896-903, 2008.

Hashmi, K. H., Zakria, G., Raza, M. B., and Khalil, S.: Optimization of process parameters for high speed machining of Ti-6Al-4V using response surface methodology, Int. J. Adv. Manuf. Tech., 85, 1847-1856, 2016.

Hong, S. Y.: Lubrication mechanisms of LN2 in ecological cryogenic machining, Mach. Sci. Technol., 10, 133-155, 2006.

Hong, S. Y. and Ding, Y.: Cooling approaches and cutting temperatures in cryogenic machining of Ti-6Al-4V, Int. J. Mach. Tool. Manu., 41, 1417-1437, 2001.

Hong, S. Y., Ding, Y., and Ekkens, R. G.: Improving low carbon steel chip breakability by cryogenic chip cooling, Int. J. Mach. Tool. Manu., 39, 1065-1085, 1999.

Hong, S. Y., Markus, I., and Jeong, W.-C.: New cooling approach and tool life improvement in cryogenic machining of titanium alloy Ti-6Al-4V, Int. J. Mach. Tool. Manu., 41, 2245-2260, 2001

ISO standard: ISO-3685, Tool-life Testing with Single Point Turning Tools, International Organization for Standardization (ISO), Geneva, Switzerland, 1993.

Jaffery, S. I. and Mativenga, P. T.: Assessment of the machinability of Ti-6Al-4V alloy using the wear map approach, Int. J. Adv. Manuf. Tech., 40, 687-696, https://doi.org/10.1007/s00170-0081393-9, 2008.

Jaffery, S. I. and Mativenga, P.: Study of the use of wear maps for assessing machining performance, P. I. Mech. Eng. B-J. Eng., 223, 1097-1105, 2009. 
Jaffery, S. H. I., Khan, M., Ali, L., Khan, H. A., Mufti, R. A., Khan, A., Khan, N., and Jaffery, S. M.: The potential of solar powered transportation and the case for solar powered railway in Pakistan, Renewable and Sustainable Energy Reviews, 39, 270-276, 2014.

Jaffery, S. H. I., Khan, M., Ali, L., and Mativenga, P. T.: Statistical analysis of process parameters in micromachining of Ti-6Al-4V alloy, P. I. Mech. Eng. B-J. Eng., 230, 1017-1034, https://doi.org/10.1177/0954405414564409, 2015.

Jawahir, I., Attia, H., Biermann, D., Duflou, J., Klocke, F., Meyer, D., Newman, S., Pusavec, F., Putz, M., and Rech, J.: Cryogenic manufacturing processes, CIRP annals, 65, 713-736, 2016.

Kalyan, C. and Samuel, G.: Cutting mode analysis in high speed finish turning of AlMgSi alloy using edge chamfered PCD tools, J. Mater. Process. Tech., 216, 146-159, 2015.

Kaynak, Y., Lu, T., and Jawahir, I. S.: Cryogenic MachiningInduced Surface Integrity: A Review and Comparison with Dry, MQL, and Flood-Cooled Machining, Mach. Sci. Technol., 18, 149-198, https://doi.org/10.1080/10910344.2014.897836, 2014.

Khatri, A. and Jahan, M. P.: Investigating tool wear mechanisms in machining of Ti-6Al-4V in flood coolant, dry and MQL conditions, Procedia Manufacturing, 26, 434-445, 2018.

Kitagawa, T., Kubo, A., and Maekawa, K.: Temperature and wear of cutting tools in high-speed machining of Inconel 718 and Ti6Al- 6V-2Sn, Wear, 202, 142-148, 1997.

Komanduri, R. and Von Turkovich, B.: New observations on the mechanism of chip formation when machining titanium alloys, Wear, 69, 179-188, 1981.

Komanduri, R., Subramanian, K., and von Turkovich, B.: High speed machining: presented at the Winter Annual Meeting of the American Society of Mechanical Engineers, 9-14 December 1984, New Orleans, Louisiana, 1984,

Kumar, K. K. and Choudhury, S.: Investigation of tool wear and cutting force in cryogenic machining using design of experiments, J. Mater. Process. Tech., 203, 95-101, 2008.

Laperrire, L. and Reinhart, G.: CIRP encyclopedia of production engineering, Springer Publishing Company, Incorporated, 2014.

Li, W. and Kara, S.: An empirical model for predicting energy consumption of manufacturing processes: a case of turning process, P. I. Mech. Eng. B-J. Eng., 225, 1636-1646, 2011.

López de lacalle, L. N., Pérez, J., Llorente, J. I., and Sánchez, J. A.: Advanced cutting conditions for the milling of aeronautical alloys, J. Mater. Process. Tech., 100, 1-11, https://doi.org/10.1016/S0924-0136(99)00372-6, 2000.

Lu, T., Kudaravalli, R., and Georgiou, G.: Cryogenic machining through the spindle and tool for improved machining process performance and sustainability: Pt. I, system design, Procedia Manufacturing, 21, 266-272, 2018.

Lundgren, A., Sennerby, L., Lundgren, D., Taylor, A., Gottlow, J., and Nyman, S.: Bone augmentation at titanium implants using autologous bone grafts and a bioresorbable barrier. An experimental study in the rabbit tibia, Clin. Oral Implan. Res., 8, 82-89, 1997.

Mia, M.: Multi-response optimization of end milling parameters under through-tool cryogenic cooling condition, Measurement, 111, 134-145, https://doi.org/10.1016/j.measurement.2017.07.033, 2017.

Mia, M. and Dhar, N. R.: Prediction of surface roughness in hard turning under high pressure coolant using Artificial Neural Network, Measurement, 92, 464-474, 2016.
Mia, M. and Dhar, N. R.: Optimization of surface roughness and cutting temperature in high-pressure coolant-assisted hard turning using Taguchi method, Int. J. Adv. Manuf. Tech., 88, 739753, 2017.

Mia, M., Khan, M. A., Rahman, S. S., and Dhar, N. R.: Monoobjective and multi-objective optimization of performance parameters in high pressure coolant assisted turning of Ti-6Al-4V, Int. J. Adv. Manuf. Tech., 90, 109-118, 2017.

Mia, M., Gupta, M. K., Lozano, J. A., Carou, D., Pimenov, D. Y., Królczyk, G., Khan, A. M., and Dhar, N. R.: Multi-objective optimization and life cycle assessment of eco-friendly cryogenic $\mathrm{N}_{2}$ assisted turning of Ti-6Al-4V, J. Clean. Prod., 210, 121-133, https://doi.org/10.1016/j.jclepro.2018.10.334, 2019.

Pervaiz, S., Deiab, I., and Darras, B.: Power consumption and tool wear assessment when machining titanium alloys, Int. J. Precis. Eng. Man., 14, 925-936, https://doi.org/10.1007/s12541013-0122-y, 2013.

Prasanna, J., Karunamoorthy, L., Raman, M. V., Prashanth, S., and Chordia, D. R.: Optimization of process parameters of small hole dry drilling in Ti-6Al-4V using Taguchi and grey relational analysis, Measurement, 48, 346-354, 2014.

Ross, P. J. and Ross, P. J.: Taguchi techniques for quality engineering: loss function, orthogonal experiments, parameter and tolerance design, TS156 R12, McGraw-Hill, New York, 1988.

Sandvik: Sandvik launches CBN tool for hardpart turning, Metal Powder Report, 70, 312-313, https://doi.org/10.1016/j.mprp.2015.10.052, 2015.

Sarıkaya, M. and Güllü, A.: Multi-response optimization of minimum quantity lubrication parameters using Taguchi-based grey relational analysis in turning of difficult-to-cut alloy Haynes 25, J. Clean. Prod., 91, 347-357, 2015.

Sarwar, M., Persson, M., Hellbergh, H., and Haider, J.: Measurement of specific cutting energy for evaluating the efficiency of bandsawing different workpiece materials, Int. J. Mach. Tool. Manu., 49, 958-965, 2009.

Schulz, H. and Moriwaki, T.: High-speed Machining, CIRP Ann., 41, 637-643, https://doi.org/10.1016/s0007-8506(07)63250-8, 1992.

Schulz, H., Arnold, W., and Scherer, J.: High Speed Machining: New Technology or Slogan?, Werkstatt und Betrieb, 114, 527531, 1981.

Senevirathne, S. W. M. A. I. and Punchihewa, H. K. G.: Comparison of tool life and surface roughness with MQL, flood cooling, and dry cutting conditions with P20 and D2 steel, IOP Conf. Ser.-Mat. Sci., 244, 012006, https://doi.org/10.1088/1757899x/244/1/012006, 2017.

Shaw, M. C.: Metal cutting principles, Oxford University Press, New York, 2005.

Shokrani, A., Dhokia, V., and Newman, S. T.: Environmentally conscious machining of difficult-to-machine materials with regard to cutting fluids, Int. J. Mach. Tool. Manu., 57, 83-101, 2012.

Sivaiah, P. and Chakradhar, D.: Effect of cryogenic coolant on turning performance characteristics during machining of 17-4 $\mathrm{PH}$ stainless steel: A comparison with MQL, wet, dry machining, CIRP Journal of Manufacturing Science and Technology, 21, 8696, https://doi.org/10.1016/j.cirpj.2018.02.004, 2018.

Sreejith, P. and Ngoi, B.: Dry machining: machining of the future, J. Mater. Process. Tech., 101, 287-291, 2000. 
Strano, M., Chiappini, E., Tirelli, S., Albertelli, P., and Monno, M.: Comparison of Ti6Al4V machining forces and tool life for cryogenic versus conventional cooling, P. I. Mech. Eng. B-J. Eng., 227, 1403-1408, 2013.

Sun, S., Brandt, M., and Dargusch, M.: Machining Ti-6Al-4V alloy with cryogenic compressed air cooling, Int. J. Mach. Tool. Manu., 50, 933-942, 2010a.

Sun, S., Brandt, M., and Dargusch, M.: Thermally enhanced machining of hard-to-machine materials - a review, Int. J. Mach. Tool. Manu., 50, 663-680, 2010b.

Sun, Y., Huang, B., Puleo, D. A., and Jawahir, I. S.: Enhanced Machinability of Ti-5553 Alloy from Cryogenic Machining: Comparison with MQL and Flood-cooled Machining and Modeling, Proc. CIRP, 31, 477-482, https://doi.org/10.1016/j.procir.2015.03.099, 2015.

Venugopal, K. A., Paul, S., and Chattopadhyay, A. B.: Growth of tool wear in turning of Ti-6Al-4V alloy under cryogenic cooling, Wear, 262, 1071-1078, https://doi.org/10.1016/j.wear.2006.11.010, 2007.

Warsi, S. S., Jaffery, S. H. I., Ahmad, R., Khan, M., Ali, L., Agha, M. H., and Akram, S.: Development of energy consumption map for orthogonal machining of Al 6061T6 alloy, P. I. Mech. Eng. B-J. Eng., 232, 2510-2522, https://doi.org/10.1177/0954405417703424, 2017.

Warsi, S. S., Agha, M. H., Ahmad, R., Jaffery, S. H. I., and Khan, M.: Sustainable turning using multi-objective optimization: a study of Al 6061 T6 at high cutting speeds, Int. J. Adv. Manuf. Tech., 100, 843-855, https://doi.org/10.1007/s00170-018-27592, 2018 .
Yan, J. and Li, L.: Multi-objective optimization of milling parameters-the trade-offs between energy, production rate and cutting quality, J. Clean. Prod., 52, 462-471, 2013.

Yuan, S., Yan, L., Liu, W., and Liu, Q.: Effects of cooling air temperature on cryogenic machining of Ti-6Al-4V alloy, J. Mater. Process. Tech., 211, 356-362, 2011.

Younas, M., Jaffery, S. H. I., Khan, M., Khan, M. A., Ahmad, R., Mubashar, A., and Ali, L.: Multi-objective optimization for sustainable turning Ti6A14V alloy using grey relational analysis (GRA) based on analytic hierarchy process (AHP), Int. J. Adv. Manuf. Tech., 105, 1175-1188, https://doi.org/10.1007/s00170019-04299-5, 2019.

Zain, A. M., Haron, H., and Sharif, S.: Simulated annealing to estimate the optimal cutting conditions for minimizing surface roughness in end milling Ti-6Al-4V, Mach. Sci. Technol., 14, 43-62, 2010.

Zhao, G., Hou, C., Qiao, J., and Cheng, X.: Energy consumption characteristics evaluation method in turning, Adv. Mech. Eng., 8, 1-8, 2016.

Zhao, Z. and Hong, S.: Cooling strategies for cryogenic machining from a materials viewpoint, J. Mater. Eng. Perform., 1, 669-678, 1992a.

Zhao, Z. and Hong, S.: Cryogenic properties of some cutting tool materials, J. Mater. Eng. Perform., 1, 705-714, 1992 b. 